\title{
Investigation of Biochemical Data in Pregnant Women Diagnosed with Restless Legs Syndrome
}

\author{
Meral Tugba Cimsir ${ }^{1}$, Hasan Basri Savas ${ }^{2^{*}}$
}

\author{
${ }^{1}$ Alanya Alaaddin Keykubat \\ University, School of Medicine, \\ Department of Obstetrics and \\ Gynecology, Antalya, Turkey \\ ${ }^{2}$ Alanya Alaaddin Keykubat \\ University, School of Medicine, \\ Department of Medical \\ Biochemistry, Antalya, Turkey
}

\section{Correspondence:}

Hasan Basri Savas

Address: Alanya Alaaddin Keykubat University, School of Medicine, Department of Medical Biochemistry, Antalya, Turkey Email: hasan.savas@alanya.edu.tr

\begin{abstract}
Objective: Restless legs syndrome is a disorder that negatively affects quality of life. Pregnancy increases the frequency of restless leg syndrome. Symptoms that occur during pregnancy can become permanent. This study aimed to investigate the possible relationship between restless legs syndrome and biochemical parameters.

Method: Alanya Alaaddin Keykubat University Education and Research Hospital was included in our randomly selected 100 pregnant women that applied to the Gynecology and Obstetrics outpatient clinic. The demographic characteristics and laboratory results of the patients were recorded. Patients were divided into two groups: one group with restless leg syndrome, and one group without. It was investigated whether there is a statistically significant difference between the demographic characteristics, blood biochemical levels, and hormonal levels between the two groups.
\end{abstract}

Results: Age, height, weight, body mass index, ferritin with pregnancy week, magnesium, vitamin $\mathrm{D}$, vitamin $\mathrm{B} 12$, thyroid stimulant hormone (TSH), hemoglobin, calcium, and aspartate aminotransferase / alanine aminotransferase (AST/ALT) levels were similar between the two groups ( $p>0.05)$.

Conclusion: Restless legs syndrome is seen in about a third of the pregnancies. Pregnant patients do not come to the doctor with this complaint, because leg complaints are a normal condition caused by pregnancy. For this reason, they continue to live with symptoms of restless leg syndrome and endure this problem. However, this disease can be diagnosed with specific inquiries of physicians regarding restless leg syndrome. Although this study could establish no significant relationship between routine biochemical parameters and RLS, it is essential to examine the possible relationship in larger patient groups in terms of evidencebased medicine.

Keywords: restless legs syndrome, pregnancy, vitamin D, ferritin, magnesium

\section{INTRODUCTION}

Restless legs syndrome (RLS) is a health condition of unpleasant leg sensations that typically occurs before the onset of sleep, causing a very strong urge to move the legs [1]. Its symptoms appear at rest, are relieved with movement, and often worsen in the evening. It was first described by Thomas Willis in 1685 in patients suffering from insomnia and restlessness in the legs. Later, in 1945, Dr. Karl-Axem Ekbom used the definitions of "irritable legs" and "restless legs", and this health issue has been also defined as Ekbom syndrome [2].
Ekbom identified RLS symptoms and described pregnancy as a cause of RLS $[3,4]$. According to its etiology, RLS can be classified as primary (idiopathic) and secondary types. Secondary RLS is associated with various conditions such as iron deficiency, diabetes, uremia, pregnancy, Parkinson's disease, neuropathy, myelopathy, rheumatoid arthritis, and antipsychotic or antidepressant medication use $[5,6]$.

RLS is commonly associated with pregnancy, and RLS symptoms negatively affect quality of life in pregnant women [7]. The prevalence of RLS among pregnant 
Table 1. Diagnostic Criteria for Restless Legs Syndrome

A. Basic Criteria

1. The urge to move the legs, often accompanied by unpleasant sensations of leg paresthesia and dysesthesia

2. Unpleasant sensations alleviated by movement

3. Symptoms worsen at rest and are partially alleviated with movement.

4.Symptoms worsen in the evening and at night

B. Supporting Criteria

1. Positive family history in primary restless leg syndrome (seen in more than $50 \%$ of patients)

2. Positive response to dopaminergic therapy

3. Sleep disturbances accompanied by periodic limb movements during sleep (seen in $85 \%$ of patients)

women varies between $10 \%$ and $34 \%[7,8,9,10,11]$. In pregnant women, typically, there is complete remission of symptoms soon after parturition; however, in some patients, symptoms may continue postpartum [8].

The key to diagnosing RLS is a careful anamnesis. It is diagnosed based on clinical criteria set by the International Restless Legs Syndrome Study Group (IRLSSG) in 1995 and revised in 2002 [12]. The revised criteria consist of essential and supportive diagnostic criteria (Table 1).

The supportive criteria help to distinguish RLS from other movement disorders such as akathisia or leg cramps.

The pathophysiology of primary RLS is still unknown. Many factors can contribute to it. The most discussed ones include nigrostriatal dopaminergic system dysfunction, lack of iron and ferritin, and genetic factors. Indeed, a genetic factor in abnormal iron metabolism can lead to insufficient dopaminergic function. Recently, thyroid hormone (TH) has been found to play a role in RLS pathophysiology $[13,14,16]$.

Hormonal (prolactin, progesterone, and estrogen levels), psychomotor and behavioral changes, sleep habits, and changes in folic acid-iron levels during pregnancy may affect the development of RLS $[13,15,16]$.

As RLS is not one of the first diagnoses that come to mind of gynecologists and obstetricians, it is not a disease that can be diagnosed easily. Since pregnant patients think that the disturbing sensations in their legs are a normal health condition caused by pregnancy, the rate of their consulting a doctor due to this complaint is very low. Therefore, gynecologists and obstetricians can diagnose RLS only through a detailed anamnesis.

This study aimed to determine the prevalence of RLS during pregnancy and possible factors affecting its etiology.

\section{MATERIALS AND METHODS}

This randomized controlled study was conducted in the gynecology and obstetrics department of Alanya Alaaddin Keykubat University (ALKU) Training and Research Hospital between January and April of 2020. The Alaaddin Keykubat University Ethics Committee approval number is 19/12/2019 14-4.
A total of 100 pregnant women who visited the Gynecology and Obstetrics outpatient clinic of ALKU Training and Research Hospital between January and April of 2020 and agreed to participate in the study were included in the study. An informed consent form was signed by those who participated in the study.

One pregnant woman was excluded from the study due to the diagnosis of gestational diabetes. The study completed 99 pregnant women who did not have a chronic disease and who received iron and multivitamins. A survey form was used to evaluate their demographic and pregnancy characteristics and RLS symptoms with a face-to-face interview technique. The patients were diagnosed with RLS when they responded "yes" to all questions in the form consisting of 4 questions created by the IRLSSG [12].

Pregnant women were divided into two groups: those with and without RLS. An independent samples $t$ test was performed to determine whether there was a statistically significant difference in their age, height, weight, body mass index, gestational week, and levels of ferritin, magnesium, vitamin $\mathrm{D}$, vitamin $\mathrm{B} 12$, thyroid stimulating hormone (TSH), hemoglobin, calcium, aspartate aminotransferase / alanine aminotransferase (AST / ALT), urea, and creatinine.

The Pearson chi-square test, Fisher's exact test, and two independent samples $t$ tests were used for statistical comparisons. Categorical variables were presented in number, percentage, and mean \pm standard deviation. A p value of less than 0.05 was considered statistically significant. Data were evaluated using ready-made statistics software (IBM SPSS Statistics 18; SPSS Inc., Chicago, IL, USA) [17].

\section{RESULTS}

The mean age of pregnant women was $29.48 \pm 6.01$ years. The mean age of those with and without RLS was $29.2 \pm 5.9$ and $29.57 \pm 6.09$ years, respectively. There was no statistically significant difference between the two groups in terms of age ( $p>0.05)$. A total of 31 pregnant women responded "yes" to all questions of the RLS diagnosis criteria, whereby the prevalence of RLS during pregnancy was determined as $31 \%$. No statistically significant difference was found between those with and without RLS in terms of age, height, weight, and body mass index (Table 2). 
Biochemical Data in Pregnant Women Diagnosed with Restless Legs Syndrome

Table 2. Comparison of the demographic characteristics of pregnant women

\begin{tabular}{cccc}
\hline Characteristic & $\begin{array}{c}\text { Pregnant women without RLS } \\
\text { n: } \mathbf{6 8}\end{array}$ & $\begin{array}{c}\text { Pregnant women with RLS } \\
\mathbf{n}: 31\end{array}$ & p value \\
\hline Age (years) & $29.57 \pm 6.092$ & $29.29 \pm 5.923$ & 0.829 \\
\hline Height (cm) & $161 \pm 6.638$ & $162.45 \pm 6.153$ & 0.305 \\
\hline Weight (kilogram) & $71.52 \pm 13.241$ & $71.61 \pm 10.566$ & 0.973 \\
\hline BMI (kg/m²) & $27.47 \pm 4.499$ & $27.23 \pm 4.485$ & 0.805 \\
\hline Pregnancy Week & $27.24 \pm 8.929$ & $27.58 \pm 9.942$ & 0.864 \\
\hline
\end{tabular}

${ }^{*}$ Mean \pm SD, BMI: Body Mass Index

Table 3. Comparison of the laboratory findings of pregnant women

\begin{tabular}{cccc}
\hline Laboratory finding & RLS $(-)$ & RLS $(+)$ & p value \\
\hline Ferritin $(\mathrm{ng} / \mathrm{ml})^{*}$ & $17.14 \pm 16.16$ & $14.30 \pm 15.54$ & 0.413 \\
\hline Magnesium $(\mathrm{mg} / \mathrm{dl})^{*}$ & $1.77 \pm 0.15$ & $1.76 \pm 0.13$ & 0.622 \\
\hline D vitamin $(\mu \mathrm{g} / \mathrm{l})^{*}$ & $8.88 \pm 4.404$ & $9.65 \pm 5.67$ & 0.465 \\
\hline Vitamin D $(\mu \mathrm{g} / \mathrm{l})^{*}$ & $302.25 \pm 152.51$ & $337.42 \pm 222.76$ & 0.362 \\
\hline TSH $(\mu \mathrm{u} / \mathrm{ml})^{*}$ & $1.97 \pm 1.34$ & $2.09 \pm 1.14$ & 0.660 \\
\hline Hemoglobin $(\mathrm{g} / \mathrm{dl})^{*}$ & $11.37 \pm 1.403$ & $11.31 \pm 1.32$ & 0.826 \\
\hline Calcium $(\mathrm{mg} / \mathrm{dl})^{*}$ & $8.75 \pm 0.39$ & $8.76 \pm 0.43$ & 0.954 \\
\hline ALT $(\mathrm{u} / \mathrm{l})^{*}$ & $16.82 \pm 20.38$ & $16.10 \pm 17.908$ & 0.865 \\
\hline AST $(\mathrm{Iu} / \mathrm{l})^{*}$ & $17.25 \pm 8.56$ & $17.32 \pm 10.83$ & 0.971 \\
\hline Urea $(\mathrm{mg} / \mathrm{dl})^{*}$ & $16.74 \pm 5.45$ & $15.03 \pm 3.85$ & 0.120 \\
\hline Creatinine $(\mathrm{mg} / \mathrm{dl})^{*}$ & $0.60 \pm 0.104$ & $0.59 \pm 0.048$ & 0.317
\end{tabular}

${ }^{* *}$ Mean \pm SD, ALT: Alanine aminotransferase, AST: Aspartate aminotransferase, RLS: Restless leg syndrome, TSH: Thyroid stimulating hormone

Both groups had similar levels of ferritin, vitamin D, vitamin B12, and TSH ( $>$ > 0.05) (Table 3).

In addition, there was no statistically significant difference between the two groups according to their hemoglobin values ( $p>0.05)$. There was also no statistically significant difference between them in terms of biochemical parameters such as magnesium, calcium, AST/ALT, urea, and creatinine $(\mathrm{p}>0.05)$.

\section{DISCUSSION}

Studies show that the prevalence of RLS among pregnant women ranges from $10 \%$ to $34 \%$ [7-11]. Epidemiological studies have reported the prevalence of RLS in pregnancy between $11 \%$ and $22.5 \%$ [19-22]. Turkish studies have found that the prevalence of RLS during pregnancy varies between $19 \%$ and $26 \%[23,24]$. This study determined the prevalence of RLS during pregnancy as $31 \%$, which seems compatible with the literature.

There is a close relationship between obesity and RLS. Some studies have reported that the prevalence of RLS increases with body mass index (BMI) [26]. However, the relationship between BMI and RLS during pregnancy has not been clearly demonstrated yet. Studies of the relationship between pregnancy and RLS have not found a relationship between BMI and RLS [23]. In their study of 500 patients,
Çakmak et al. found that the prevalence of RLS was higher in pregnant women with a high BMI [18]. In this study, pregnant women with RLS (+) and RLS (-) had a similar BMI.

Şahin et al. found that pregnant women with and without RLS were of similar age, height, weight, and gestational week [23]. In the present study, the groups were also similar in terms of these demographic characteristics. However, this study determined that pregnant women with RLS (+) had higher gestational week, which was not statistically significant.

Tunç et al. found that although there was no statistically significant difference between pregnant women with RLS (+) and RLS (-) in terms of serum iron, ferritin, and hematocrit values. However, hemoglobin values were lower in those with RLS (+) [24]. Hübner et al. determined that hemoglobin and serum ferritin levels were similar in pregnant women with and without RLS [25]. This study found no statistically significant difference between the groups with RLS (+) and RLS (-) in terms of serum hemoglobin and hematocrit values.

In the present study, although TSH was higher in pregnant women with RLS (+) than in those with RLS (-), no statistically significant difference was found between the groups. 
Işıkay et al. reported a significant negative correlation between the severity of RLS symptoms and serum ferritin and vitamin D levels [27]. In this study, although ferritin levels were lower in the RLS (+) group, the difference was not statistically significant.

Vitamin B12 deficiency, which may develop in inflammatory bowel diseases, may play a role in the etiology of RLS. Takahara et al. reported that RLS is common in Japanese patients with inflammatory bowel diseases such as ulcerative colitis and Crohn's disease [28]. This study found no significant difference between the groups with and without RLS in terms of serum vitamin B12 levels.

Turk et al. reported that serum calcium levels were associated with the severity of RLS [29]. However, this study determined no significant relationship between calcium levels and RLS.

Pregnancy can mask RLS in women. As RLS can adversely affect pregnancy, it is important to raise awareness among physicians and others about RLS. Further studies with larger patient groups are needed to shed light on the pathophysiology and etiology of RLS.

\section{CONCLUSION}

The prevalence of RLS is high in pregnant women. RLS that occurs during pregnancy sometimes continues after pregnancy. This situation can permanently affect patients' quality of life. Studies report various relationships between RLS and biochemical parameters. Although this study could establish no significant relationship between routine biochemical parameters and RLS, it is essential to examine the possible relationship in larger patient groups in terms of evidence-based medicine.

Declaration of interest: The authors report no conflicts of interest.

Financial Disclosure: No financial support was received.

\section{REFERENCES}

1. American Sleep Disorders Association Diagnostic Classification Steering Committee. The international classification of sleep disorders: diagnostic \& coding manual, Westchester, IL: American Academy of Sleep Medicine, 2005.

2. Ekbom KA. Asthenia crurum paraesthetica (irritabl legs). New syndrome consisting of weakness, sensation of cold and nocturnal paresthesia in legs, responding to certain extent to treatment with Priscol and Doryl; note on paresthesia in general. Acta Med Scand 1944; 118: 197-209.

3. Ekbom KA. Restless legs syndrome. Neurology 1960; 10 868-73.

4. Ekbom KA. Restless leg syndrome. Acta Med Scand Suppl 1945; 158: 1-123.
5. Gabaldón Torres L, Salas Felipe J, Fernández Domínguez J, Vivancos Matellanos F, Izal E, Arpa Gutiérrez F. Restless legs syndrome. Features and impact on sleep syndrome. Neurologia. 2009; 24(4): 230-4.

6. Carrillo F, Mir P. Symptomatic causes of restless legs syndrome. Neurologia. 2009; 24: 841-4.

7. Minar M, Habanova H, Rusnak I, Planck K, Valkovic P. Prevalence and impact of restless leg syndrome in pregnancy. Neuro Endocrinol Lett. 2013; 34(5): 366-71.

8. Gupta R, Dhyani M, Kendzerska T, et al. Restless legs syndrome and pregnancy: prevalence, possible pathophysiological and mechanisms and treatment. Acta Neurolg. Scand. 2016; 133(5): 320-9.

9. Uglane MT, Westad S, Backe B Restless legs syndrome in pregnancy is a frequent disorder with a good prognosis. Acta Obstet Gynecol Scand. 2011; 90(9): 1046-8.

10. Neau JP, Porcheron A, Mathis S, Julian A, Meurice JC, Paquereau J, Godeneche G, Ciron J, Bouche G Restless legs syndrome and pregnancy: a questionnaire study in the Poitiers District, France. Eur Neurol. 2010; 64(5): 268-74.

11. Manconi M, Govoni V, De Vito A, Economou NT, Cesnik E, Casetta I, Mollica G, Ferini-Strambi L, Granieri E Restless legs syndrome and pregnancy Neurology. 2004; 28; 63(6): 1065-9.

12. Allen RP, Picchietti D, Hening WA, Trenkwalder C, Walters AS, Montplaisi J, Restless Legs Syndrome Diagnosis and Epidemiology workshop at the National Institutes of Health., International Restless Legs Syndrome Study Group. Restless legs syndrome: diagnostic criteria, special considerations, and epidemiology. A report from the restless legs syndrome diagnosis and epidemiology workshop at the National Institutes of Health. Sleep Med. 2003; 4(2): 101-19.

13. Pereira JC Jr, Pradella-Hallinan M Imbalance between thyroid hormones and the dopaminergic system might be central to the pathophysiology of restless legs syndrome: a hypothesis., Lins Pessoa Hd Clinics (Sao Paulo). 2010; 65(5): 548-54.

14. Pereira JC Jr, Rocha e Silva IR, Pradella-Hallinan M Transient Willis-Ekbom's disease (restless legs syndrome) during pregnancy may be caused by estradiol-mediated dopamine overmodulation. Med Hypotheses. 2013; 80(2): 205-8.

15. Ondo W, Jankovic J. Restless leg syndrome: clinicoetiologic correlates. Neurology 1996; 47: 1435-41.

16. O'Keeffe ST. Iron deficiency with normal ferritin levels in restless legs syndrome. Sleep Med 2005; 6: 281-2.

17. Doğan N, Başokçu TO. Comparison of Factor Analysis and Progressive Clustering Analysis Results Applied for Statistic Attitude Scale, Journal of Measurement and Evaluation in Education and Psychology, 2010; 1(2): 6571. 
18. Cakmak B. Restless leg syndrome in pregnancy. Perinatal Journal 2014; 22(1): 1-5. doi: 10.2399/prn.14.0221001

19. Sarberg M, Josefsson A, Wirehn AB, Svanborg E. Restless legs syndrome during and after pregnancy and its relation to snoring. Acta Obstet Gynecol Scand 2012; 91: 850-5.

20. Goodman JDS, Brodie C, Ayida GA. Restless leg syndrome in pregnancy. Br Med J 1988; 297: 1101-2.

21. Walters AS. Toward a better definition of the restless legs syndrome. The International Restless Legs Syndrome Study Group. Mov Disord 1995; 10: 634-42.

22. Balendran J, Champion D, Jaaniste T, Welsh A. A common sleep disorder in pregnancy: restless legs syndrome and its predictors. Aust N Z J Obstet Gyneacol 2011; 51: 262-4.

23. Şahin KF, Köken G, Coşar E, Solak Ö, Saylan F, Fidan F, Ünlü M. Restless leg syndrome frequency in pregnancies. Journal of Turkish Gynecology and Obstetric Society 2007; 4: 246-9.

24. Tunc T, Karadag YS, Dogulu F, Inan LE. Predisposing factors of restless legs syndrome in pregnancy. Mov Disord 2007; 22: 627-31.
25. Hübner A, Krafft A, Gadient S, Werth E, Zimmermann $\mathrm{R}$, Bassetti CL. Characteristics and determinants of restless legs syndrome in pregnancy: a prospective study. Neurology 2013; 80: 738-42.

26. Gao X, Schwarzschild MA, Wang H, Ascherio A. Obesity and restless legs syndrome in men and women. Neurology 2009; 72: 1255-61.

27. Işıkay S. Restless leg syndrome in children with celiac disease. Turk J Pediatr. 2018; 60(1): 70-5. doi: 10.24953/turkjped.2018.01.010.

28. Takahara I, Takeshima F, Ichikawa T, Matsuzaki T, Shibata H, Miuma S, Akazawa Y, Miyaaki H, Taura N, Nakao. Prevalence of Restless Legs Syndrome in Patients with Inflammatory Bowel Disease. Dig Dis Sci. 2017; 62(3): 761-7. doi: 10.1007/s10620-016-4420-y.

29. Ayla CT, Ozkurt S, Turgal E, Sahin F. The association between the prevalence of restless leg syndrome, fatigue, and sleep quality in patients undergoing hemodialysis. Saudi Med J. 2018; 39(8): 792-8. doi: 10.15537/smj.2018.8.22398. 